\title{
Synthesis of silver nanoparticles from Sargassum tenerrimum and screening phytochemicals for its antibacterial activity
}

\author{
P Kumar $^{1}$, S Senthamil Selvi ${ }^{2}$, A Lakshmi Prabha ${ }^{2}$, K Prem Kumar ${ }^{3}$, R S Ganeshkumar ${ }^{1}$ and M Govindaraju $^{{ }^{*}}$ \\ ${ }^{1}$ Department of Environmental Biotechnology, Bharathidasan University, Tiruchirappalli - 24, India \\ ${ }^{2}$ Department of Plant Science, Bharathidasan University, Tiruchirappalli, India \\ ${ }^{3}$ Department of Biomedical Science, Bharathidasan University, Tiruchirappalli, India. \\ * Corresponding author: mgrasu@gmail.com(M. Govindaraju)
}

\begin{abstract}
Synthesis of nanomaterials by biological approach is innovative, cheaper and environmental friendly and requires less-labor. In this regard, the present study focused on the synthesis of silver nanoparticles from the extract of Sargassum tenerrimum. Synthesized silver nanoparticles were wellcharacterized by UV-Visible Spectroscopy (UV-Vis), Fourier-Transform Infra-red Spectroscopy (FT-IR), Transmission Electron Microscopy analysis (TEM) and Dynamic Light Scattering (DLS). It was found that spherical shaped nanoparticles of size $20 \mathrm{~nm}$ were found in TEM analysis and showed effective anti-bacterial activity against standard reference strains. Altogether, extracts from seaweed were screened for phytochemicals followed by FT-IR prediction to reveal chemical functional groups present. The results showed that the anti-bacterial activity of silver nanoparticles was comparably higher than the phytochemicals present. Therefore, the present study elucidates silver nanoparticles can play a vital role in nano-based therapy in future.
\end{abstract}

Keywords: Sargassum tenerrimum, Silver nanoparticles, Phytochemicals, TEM, Antibacterial activity

Citation: P. Kumar, et al. Synthesis of silver nanoparticles from Sargassum tenerrimum and screening phytochemicals for its anti-bacterial activity. Nano Biomed. Eng. 2012, 4(1), 12-16.DOI: 10.5101/nbe.v4i1.p12-16.

\section{Introduction}

The non-polluting nanotechnologies have revolutionized the production of nanomaterials as environmentally safe products. Several chemicals used in the synthesis of nanoparticles are toxic which leads to environmental pollution [1]. Therefore, an alternative methodology is mandatory to trounce the toxic and polluting chemicals, along with various reducing and stabilizing agents. The naturally available biological resources can be an alternative source for the biosynthesis of nanoparticles [2-4]. Seaweeds are group of marine plants that are rich source of biologically active substances with biomedical applications. Hence, biosynthesis of nanoparticles using seaweeds has turned much of our attention towards the utilization of renewable marine resources.

Historically, silver metal has been widely used as a therapeutic agent for curing diseases. In addition, soluble silver salts are more advantageous over epilepsy, nicotine addiction, gastroenteritis, stomatitis [5, 6] and sexually transmitted diseases [7]. Consequently, biosynthesized silver nanoparticles have a promising role in biomedical applications. It is well understood that silver nanoparticles possess elevated surface area that hinder microbial growth compared to silver metal as a bulk [8]. These nanoparticles can directly interact with bacterial cells causing oxidative stress that result in deadly damage [9]. The anti-bacterial activity of silver nanoparticles depends upon the bioavailability of silver ions [10] and due to the presence of reducing agents [2].

With reference to the biological perspectives, we report on the biosynthesis of silver nanoparticles from marine brown seaweed, Sargassum tenerrimum. Recently, polysaccharides from Sargassum tenerrimum showed antiviral activity against Herpes Simplex Viruses (HSVs) [11]. 
In addition, anti-bacterial potential of brown seaweeds is impressive over human pathogens [12]. Researchers predict that bio-reduction of metal compounds by plants is due to the presence of phytochemicals [2]. Watersoluble phytochemicals such as polyphenols, flavones, organic acids and quinones are greatly responsible for immediate reduction. Taking this as an initiative, we aimed to instigate the anti-bacterial efficacy of rapidly biosynthesized silver nanoparticles from Sargassum tenerrimum with that of its phytochemical constituents.

\section{Materials and methods}

\subsection{Preparation of aqueous seaweed extract}

Sargassum tenerrimum was collected by hand picking method at a depth of $1-2$ meter in Gulf of Mannar,

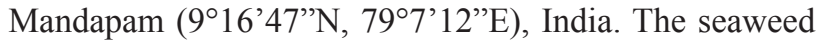
was surface sterilized with tap water to remove extraneous substances followed by distilled water. The seaweed is identified, shade dried for 15 days and powdered using mixer grinder. Later, aqueous extract was prepared by dissolving $200 \mathrm{mg}$ of powdered seaweed in $100 \mathrm{ml}$ of sterile distilled water. The extract was heated at $60{ }^{\circ} \mathrm{C}$ for 20 mins, centrifuged at 8,000 rpm and the supernatant was used throughout the study.

\subsection{Synthesis and characterization of silver nano- particles (AgNPs)}

In an Erlenmeyer's flask, $95 \mathrm{ml}$ of $1 \mathrm{mM}$ Silver nitrate $\left(\mathrm{AgNO}_{3}\right)$ solution was prepared using deionized water and $5 \mathrm{ml}$ of aqueous seaweed extract was added [13]. The reaction mixture was gradually heated to $90^{\circ} \mathrm{C}$ for $20 \mathrm{mins}$ and the change in color was envisaged as the evidence of bioreduction. Characterization of silver nanoparticles was performed in sequence using UV-Visible Spectrophotometer (Shimadzu - 2450), FT-IR (Spectrum RX-1 instrument) and Transmission Electron Microscopic (Tecnai 10 instrument). The particle size distribution and zeta potential analysis of silver nanoparticles was evaluated using Dynamic Light Scattering measurement (Malvern - zetasizer - nano-Z590).

\subsection{Preliminary screening of phytochemicals}

Powdered seaweed of $10 \mathrm{~g}$ was soaked in $100 \mathrm{ml}$ of methanol to obtain crude extract. The mixture was then centrifuged at $5000 \mathrm{rpm}$ for 20 minutes at $4{ }^{\circ} \mathrm{C}$ and filter sterilized using $0.2 \mu \mathrm{m}$ membrane syringe. A fraction of seaweed extract was subjected to phytochemical screening as described by Harborne, 1998 [14]. Natural chemical groups such as amino acids, alkaloids, carbohydrates, flavonoids, saponins, sterols, tannins, terpenoids, proteins and phenolic compounds were probed. The methanolic extract was further exemplified by FT-IR spectroscopic studies to reveal the characteristic functional group present.

\subsection{Anti-bacterial efficacy by disk diffusion method}

Bacterial cultures such as Bacillus cereus (MTCC 1272), Escherichia coli (MTCC 1687), Klebsiella pneumoniae (MTCC 530), Proteus mirabilis (MTCC 425), Pseudomonas aeruginosa (MTCC 1688), Salmonella typhii (MTCC 531), Shigella flexneri (MTCC 1457) Staphylococcus aureus (MTCC 96) and Vibrio cholerae (MTCC 3906) were obtained from Microbial Type Culture Collection (MTCC), Indian Institute of Microbial Technology, Chandigarh, India. Disk diffusion method was adopted to evaluate the anti-bacterial efficacy of aqueous extract, biosynthesized silver nanoparticles and methanol extract from the Sargassum tenerrimum along with $1 \mathrm{mM}$ of silver nitrate as positive control. Freshly prepared Luria Bertani (LB) agar plates were inoculated with exponential bacterial cultures $\left(10^{6} \mathrm{CFU}\right.$ $\left.\mathrm{mL}^{-1}\right)$ by spread plate technique. Sterile antibiotic disks (HIMEDIA - $6 \mathrm{~mm}$ ) were impregnated with $30 \mu \mathrm{l}$ of test samples and placed on the agar plates. The plates were incubated at $37{ }^{\circ} \mathrm{C}$ for $24 \mathrm{~h}$ and Zone of Inhibition (ZoI) was measured, mean while the experiments were performed in triplicates.

\section{Results and discussion}

\subsection{Synthesis and characterization of silver nano- particles}

Several reports have been employed for the synthesis of silver nanoparticles for its beneficial applications. Recently, seaweeds have been identified as the potential source for synthesizing nanoparticles while Singaravelu et al [3] have synthesized gold nanoparticles from Sargassum wightii extract within $24 \mathrm{~h}$ of incubation time. Similarly, we have synthesized silver nanoparticles from the extract of Sargassum tenerrimum rapidly within $20 \mathrm{~min}$. Endpoint with prominent color change (Fig. 1) indicates the excitation of surface plasmon resonance due to reduction of silver nitrate [14]. Longitudinal plasmon vibrations corresponding to silver nanoparticles were convincing with UV spectral peak at $420 \mathrm{~nm}$ and with no absorption peak in control i.e. without reductant (Fig. 2). This clearly indicates the interaction between silver ions and biomolecules present in the aqueous seaweed extract. Intensity of band increased upon varying time without any shift in peak position.

According to transmission electron microscope, the morphology of silver nanoparticles observed to be spherical with an average size of $20 \mathrm{~nm}$ (Fig. 3). Particle size distribution was plotted using the results obtained from Dynamic Light Scattering analysis (DLS) with a maximum intensity at $45 \mathrm{~nm}$ (Fig. 4a) and zeta potential measurements disclosed that the silver nanoparticles are highly stable with a value of $-27 \mathrm{mV}$ (Fig. 4b). FT-IR bands corresponding to silver nanoparticles are at 3431 $\mathrm{cm}^{-1}, 2386 \mathrm{~cm}^{-1}, 2073 \mathrm{~cm}^{-1}, 1637 \mathrm{~cm}^{-1}$ and $693 \mathrm{~cm}^{-1}$ (Fig. 5a). The absorption band corresponding to $3431 \mathrm{~cm}^{-1}$ is due to N-H stretching vibrations of peptide linkages and hydroxyl stretch vibrations of carboxylic acid groups demonstrating the presence of polyphenols [15]. Further, amide - I band which is due to carbonyl stretch vibrations in the amide linkages of protein at $1637 \mathrm{~cm}^{-1}$ representing polyphenols [16]. The CO peak at $2386 \mathrm{~cm}^{-1}$ and 2073 


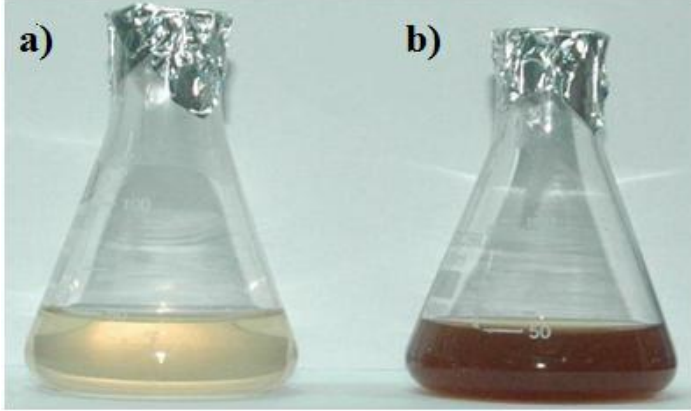

Fig. 1 Silver nanoparticles using Sargassum tenerrimum a) before synthesis (control), b) after synthesis (synthesized silver nanoparticles)

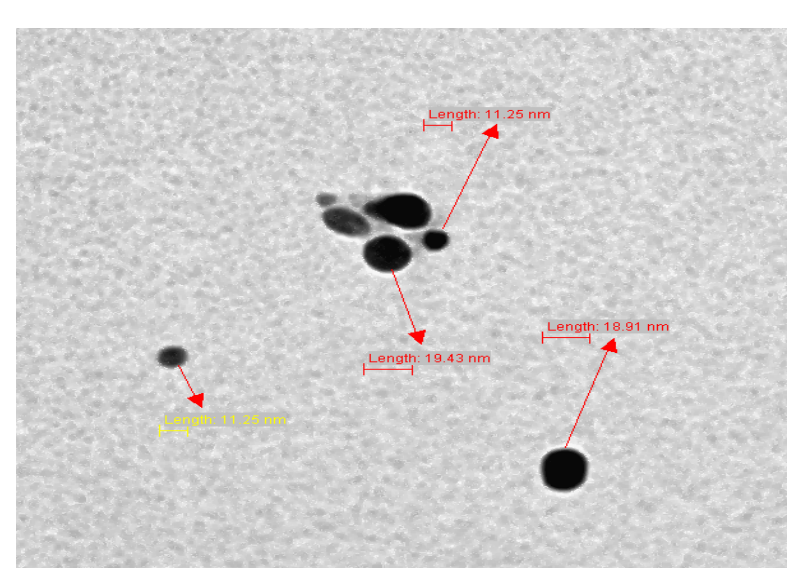

Fig. 3 TEM images obtained after 10 fold dilution of purified silver nanoparticles using Sargassum tenerrimum. The range of observed diameter was $100 \mathrm{~nm}$
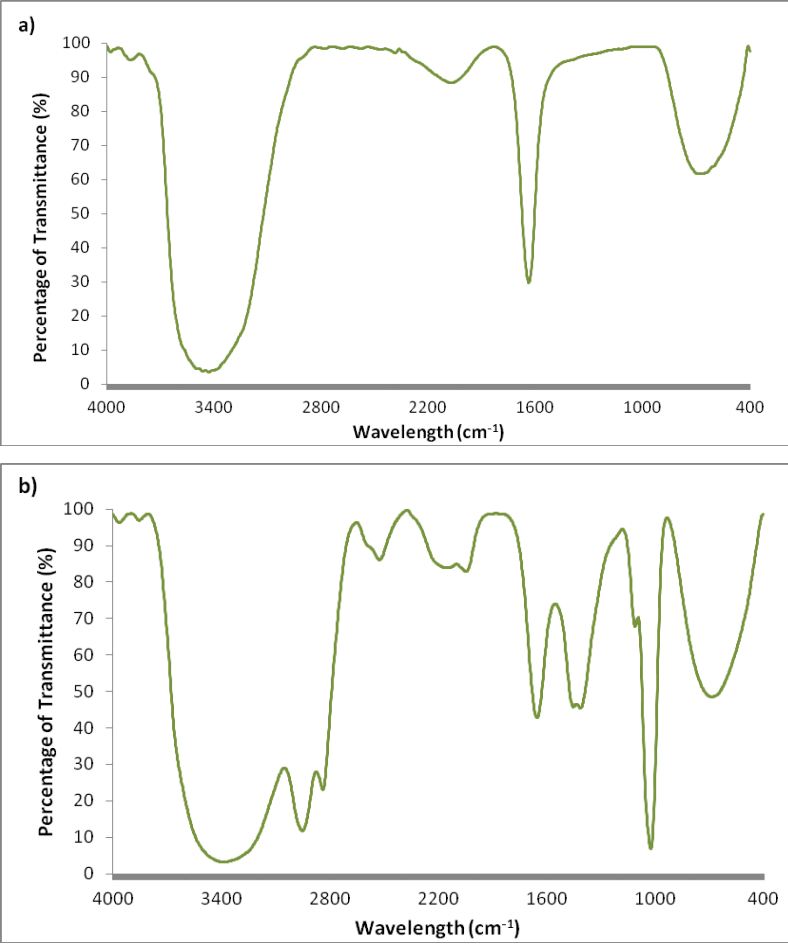

Fig. 5 FT-IR spectral patterns of Sargassum tenerrimum ranging from $4000-400 \mathrm{~cm}^{-1}$. a) Silver nanoparticles b) Phytoconstituents.

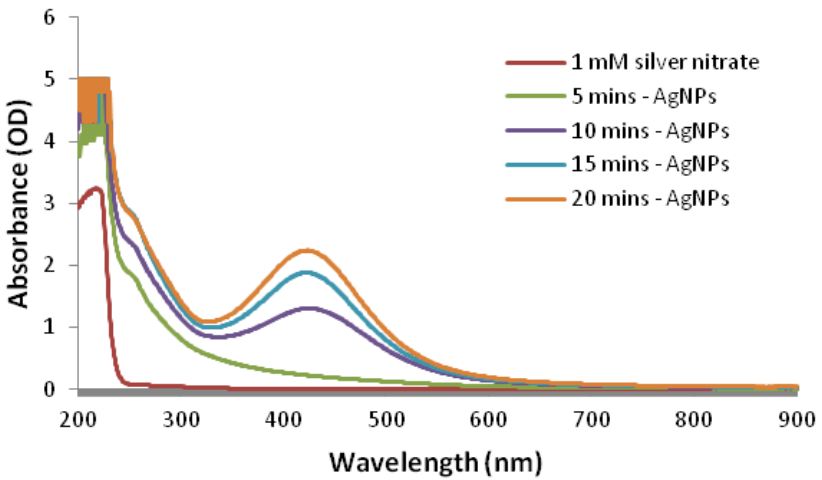

Fig. 2 UV-Vis-spectra of silver nanoparticles.

a)
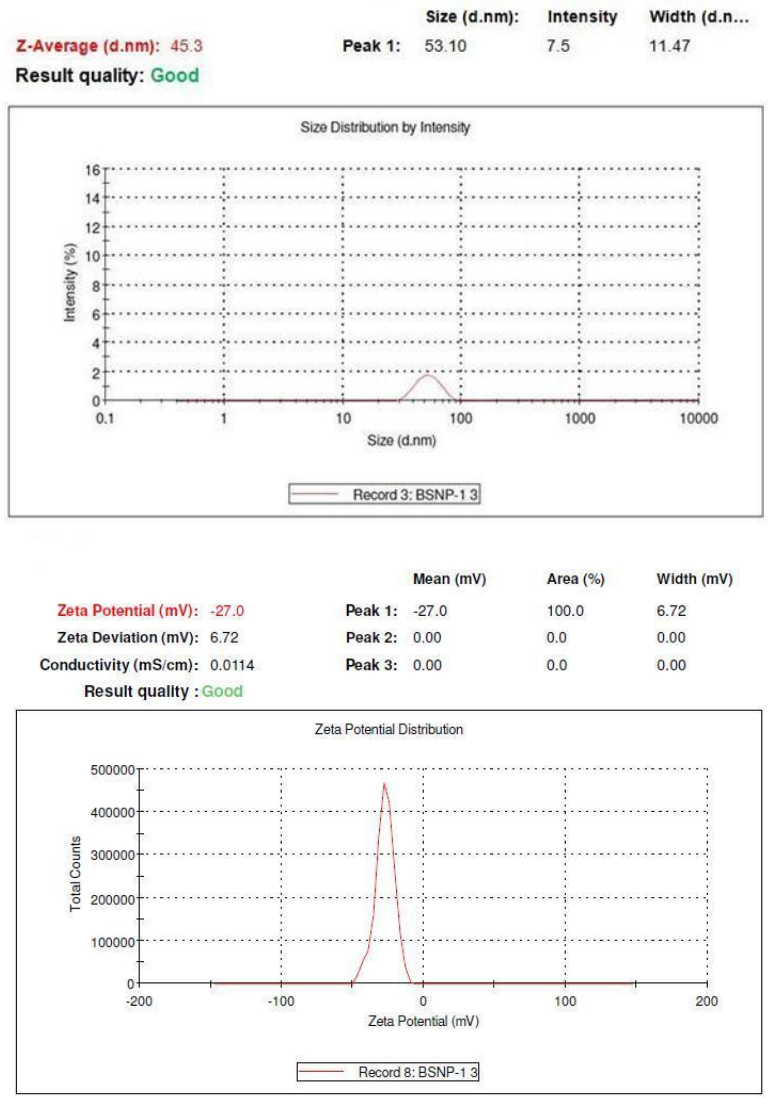

Fig. 4 Dynamic Light Scattering measurements a) Size distribution by intensity, b) Zeta potential measurements.

Table 1. Preliminary Screening of Phytochemicals $(+)$ presence $(-)$ absence

\begin{tabular}{|c|l|c|}
\hline S. No. & Phytochemicals & Result \\
\hline 1 & Amino acids & + \\
\hline 2 & Alkaloids & + \\
\hline 3 & Carbohydrates & + \\
\hline 4 & Flavonoids & + \\
\hline 5 & Saponins & + \\
\hline 6 & Sterols & + \\
\hline 7 & Tannins & + \\
\hline 8 & Proteins & + \\
\hline 9 & Phenolic compounds & + \\
\hline
\end{tabular}




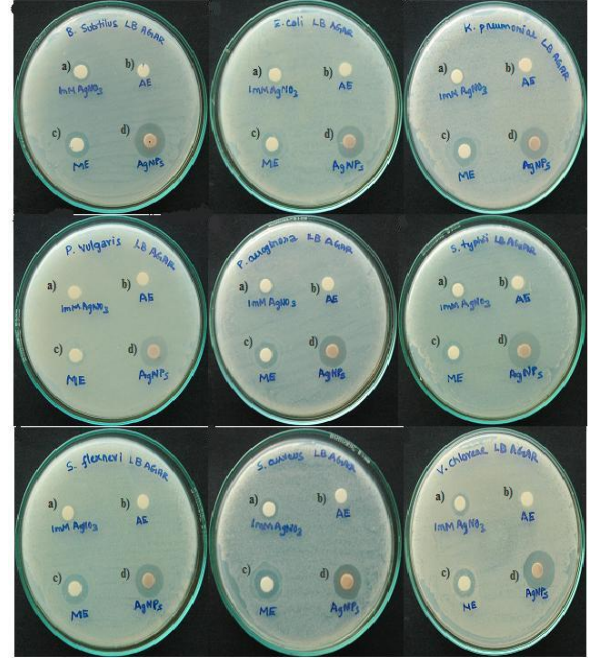

Fig. 6 Anti-bacterial activity of various extracts against nine human pathogenic strains. a) $1 \mathrm{mM}$ silver nitrate $\left(1 \mathrm{mM} \mathrm{AgNO}_{3}\right.$ - positive control) b) Aqueous Extract (AE) c) Methanol Extract (ME) d) Biosynthesized silver nanoparticles (AgNPs)

$\mathrm{cm}^{-1}$ decreases its intensity and a peak formed at $692 \mathrm{~cm}^{-1}$ is may be attributed to out of sketch blending of aromatic ring.

\subsection{Phytochemical analysis}

The preliminary phytochemical analysis of methanol extract revealed the presence of amino acids, alkaloids, carbohydrates, flavonoids, saponins, sterols, tannins, terpenoids, proteins, and phenolic compounds as shown in Table. 1. FT-IR predicts the molecular configuration of different functional group present in the seaweed extract. Considerable absorption peak were found at $3387 \mathrm{~cm}^{-1}$, $2951 \mathrm{~cm}^{-1}, 2838 \mathrm{~cm}^{-1}, 2524 \mathrm{~cm}^{-1}, 2155 \mathrm{~cm}^{-1}, 2044 \mathrm{~cm}^{-1}$, $1652 \mathrm{~cm}^{-1}, 1452 \mathrm{~cm}^{-1}, 1412 \mathrm{~cm}^{-1}, 1110 \mathrm{~cm}^{-1}, 1023 \mathrm{~cm}^{-1}$ and $686 \mathrm{~cm}^{-1}$ respectively (Fig. 5b). The peak corresponding to $3387 \mathrm{~cm}^{-1}$ indicates the presence of intermolecular hydrogen bonding with hydroxyl group with polymeric association. The peak formed at $2951 \mathrm{~cm}^{-1}, 2838 \mathrm{~cm}^{-1}$ is because of C-H stretching and symmetric stretching of methoxy groups present [17]. A small peak at 2524 $\mathrm{cm}^{-1}$ is an attribute to $\mathrm{S}-\mathrm{H}$ stretching vibration mode. The stretch between $\quad 2155 \mathrm{~cm}^{-1}-2161 \mathrm{~cm}^{-1}$ typically formed by triple $\mathrm{C} \equiv \mathrm{C}$ bond in alkynes or because of cumulative double bond in ketones [18]. A minute peak with less intensity at $1451 \mathrm{~cm}-1$ indicates the presence of asymmetric $\mathrm{CH}_{3}$ bending modes of the methyl groups of proteins [19]. The absorption peak formed at $1412 \mathrm{~cm}^{-1}$ is due stretching C-N, deformation N-H and deformation of C-H [16]. Peak at $1110 \mathrm{~cm}^{-1}$ and $1024 \mathrm{~cm}^{-1}$ is responsible for polysaccharides [20] and C-O stretch associated with glycogen [21] respectively.

\subsection{Comparative anti-bacterial activity}

Unlike previous reports [2, 3, 4], comparative antibacterial property of silver nanoparticles and methanol extract was executed. The test was carried out against nine pathogenic reference strains including both Grampositive and Gram-negative bacteria (Fig. 6). Silver

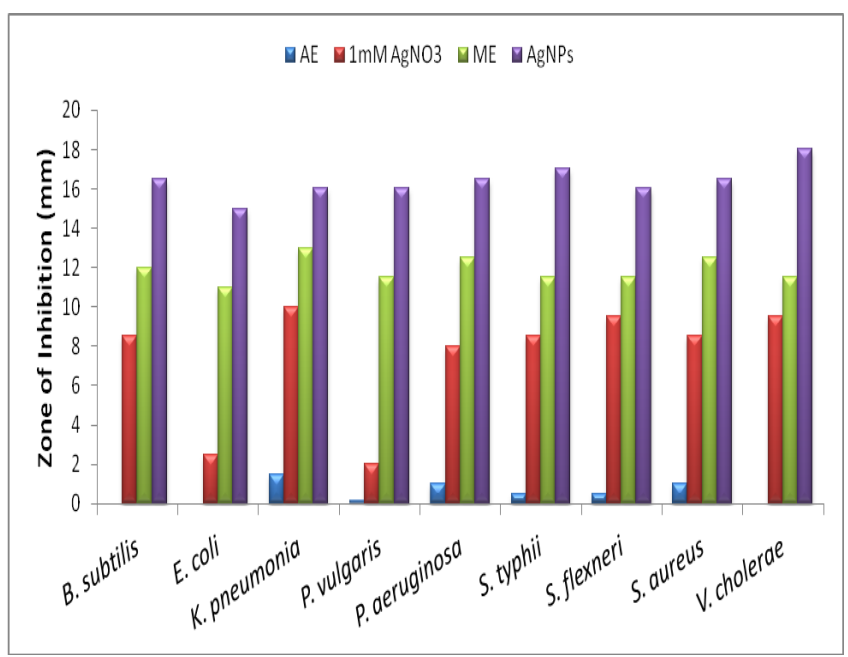

Fig. 7 Comparative anti-bacterial activity based on Zone of Inhibition (mm). a) Aqueous Extract (AE), b) $1 \mathrm{mM}$ silver nitrate $\left(\mathrm{AgNO}_{3}-\right.$ positive control), c) Methanol Extract (ME), d) Biosynthesized silver nanoparticles (AgNPs)

nanoparticles exhibited good anti-bacterial activity (more than $15 \mathrm{~mm}$ ) against all pathogens specifically to Vibrio cholerae (18 mm) which is more susceptible (Fig. 7). The aqueous extract of seaweed was found to have unclear zone of inhibition compared to $1 \mathrm{mM}$ silver nitrate as positive control. This illustrates that, silver compounds are toxic to microorganisms with strong anti-bacterial effect including multi-drug resistant bacteria [22]. Similarly, electrostatic interaction between positively charged nanoparticles and the negatively charged bacterial membrane induces cell permeability resulting in cell death [23]. Besides, methanol extract proves its efficiency when compared to aqueous extract due to the presence of secondary metabolites. Rao et al [24] have reported that 12 different species of Sargassum extract possess high anti-bacterial activity against human pathogenic bacteria. Similarly, Shelat [25] have found that methanol extract of Sargassum plagiophyllum was found to be active against Gram-positive bacteria while acetone extract of Sargassum tenerrimum showed high activity against all tested strains. The interesting information is that, green synthesis of silver nanoparticles by exploiting seaweed has immense anti-bacterial activity compared to all other extracts. The study also suggests that seaweeds containing phytochemicals can be better opted for nanoparticle synthesis. This work throws some light on futuristic research work on synthesis of nanoparticle from seaweeds towards biomedical applications.

\section{Conclusion}

To summarize, comparative anti-bacterial activity of silver nanoparticles and phytochemicals from Sargassum tenerrimum was evaluated. Silver nanoparticle were synthesized and characterized in ambient conditions with an average size of $11-20 \mathrm{~nm}$. The presence of phytochemicals as reducing agents in synthesizing nanoparticle can be potent antimicrobials in near future. The result concluded that biosynthesized nanoparticles 
10. Chen X, Schluesener HJ. Nanosilver: A nanoproduct in medical application. Toxicol Lett. 2008; 176:1-12. http://dx.doi.org/10.1016/ j.toxlet.2007.10.004

all test pathogenic strains compared to phytochemical constituents. A further study is needed to find out the

\section{Acknowledgements}

The authors are grateful to DST-NRDMS, Government of India, New Delhi for their financial assistance through major research project.

\section{References}

1. Esumi K, Kameo A, Suzuki A, Torigoe K. Preparation of gold nanoparticles in formamide and N,N-dimethylformamide in the presence of poly(amidoamine) dendrimers with surface methyl ester groups. Colloids and Surf A: Physicochem. Eng. Aspects. 2001; 189 (1-3):155-161. http://dx.doi.org/10.1016/S0927-7757(00)00811-6.

2. Prathna TC, Mathew L, Chandrasekaran N, Raichur AM, Mukherjee A. Biomimetic Synthesis of Nanoparticles: Science, Technology \& Applicability, Edited A. Mukherjee, InTech Publishers, Croatia 2010, pp. 1-20.

3. Singaravelu G, Arockiamary JS, Ganesh Kumar V, Govindaraju K. A novel extracellular synthesis of monodisperse gold nanoparticles using marine alga, Sargassum wightii Greville. Colloids Surf. B Biointerfaces. 2007; 57:97-101.http://dx.doi.org/10.1016/ j.colsurfb.2007.01.010

4. Mubarak Ali D, Sasikala M, Gunasekaran M, Thajuddin. Biosynthesis and Characterization of silver nanoparticles using marine cyanobacterium, Oscillatoria willei NTDM01. Dig. J. Nanomater. Bios. 2011; 6(2):385-390.

5. Alidaee MR, Taheri A, Mansoori P, Ghodsi SZ. Silver nitrate cautery in aphthous stomatitis: a randomized controlled trail. $\mathrm{Br}$. J. Dermatol. 2005; 153(3):521-525.http://dx.doi.org/10.1111/j.13652133.2005.06490.x

6. Tanweer F, Hanif J. Re: Silver nitrate cauterization, does concentration matter? J. Clin. Otolaryngol. 2008; 33(5):503-504. http://dx.doi.org/10.1111/j.1749-4486.2008.01803.x

7. Gougeon ML, Lecoeur H, Dulioust A, Enouf MG, Crouvoiser M, Goujard C, Debord T, Montagnier L. Programmed cell death in peripheral lymphocytes from HIV-infected persons: increase susceptibility to apoptosis of CD4 and CD8 T cells correlates with lymphocyte activation and with disease progression. J. Immunol. 1998;156: 3509-3520.

8. Shahverdi AR, Fakhimi A, Shahverdi HR, Minaian S. Synthesis and effect of silver nanoparticles on the antibacterial activity of different antibiotics against Staphylococcus aureus and Escherichia coli. Nanomedicine. 2007; 3(2):168-171.http://dx.doi.org/10.1016/ j.nano.2007.02.001

9. Li Q, Mahendra S, Lyon DY, Brunet L, Liga MV, Li D, Alvarez PJ. J. Antimicrobial nanomaterials for water disinfection and microbial control: Potential applications and implications. Water Res. 2008; 42(42):4591-4602. http://dx.doi.org/10.1016/ j.watres.2008.08.015.
11. Jha AK, Prasad K, Prasad K, Kulkarni AR. Plant system: Nature's nanofactory. Colloids Surf. B Biointerfaces. 2009; 73:219-223. http://dx.doi.org/10.1016/j.colsurfb.2009.05.018,

12. Dwivedi AD, Gopal K. Biosynthesis of silver and gold nanoparticles using Chenopodium album leaf extract. Colloids and Surf A: Physicochem. Eng. Aspects. 2010; 369:27-33. http://dx.doi. org/10.1016/j.colsurfa.2010.07.020. using plant leaf extracts. Bioprocess Biosyst. Eng. 2008; 32:79-84. http://dx.doi.org/10.1007/s00449-008-0224-6

14. Harborne JB, Phytochemical methods - A guide to modern techniques of plant analysis, Chapman and Hall Ltd, London, 1998.

15. Krishnan R, Maru GB. Isolation and analyses of polymeric polyphenols fractions from black tea. Food Chem. 2006; 94 : 331-340. http://dx.doi.org/10.1016/j.foodchem.2004.11.039,

16. O'Coinceanainn MO, Astill C, Schumm S. Potentiometric FTIR and NMR studies of the complexation of metals with theaflavin. Dalton Trans. 2003; 5:801-807. http://dx.doi.org/10.1039/b211102k

17. Kasthuri J, Veerapandian S, Rajendran N. Biological synthesis of silver and gold nanoparticles using apiin as reducing agent. Colloids Surf. B Biointerfaces. 2009; 68:55-60.http://dx.doi.org/10.1016/ j.colsurfb.2008.09.021

18. Dovbeshko GI, Gridina NY, Kruglova EB, Pashchuk OP. FTIR spectroscopy studies of nucleic acid damage. Talenta. 1997; 53: 233246. http://dx.doi.org/10.1016/S0039-9140(00)00462-8

19. Nyquist NA, Interpreting Infrared, Raman and Nuclear Magnetic Resonance Spectra, Vol. 1, Academic Press, London, 2001.

20. Fujioka N, Morimoto Y, Arai T, Kikuchi M. Discrimination between normal and malignant human gastric tissues by Fourier transform infrared spectroscopy. Cancer Detect. Prev. 2004; 28:32-36. http:// dx.doi.org/10.1016/j.cdp.2003.11.004

21.Shetty G, Kedall C, Shepherd N, Stone N, Barr. H. Raman spectroscopy: elucidation of biochemical changes in carcinogenesis of oesophagus. Brit. J. Cancer. 2006; 94:1460-1464.http://dx.doi. org/10.1038/sj.bjc. 6603102

22. Wood BR, Quinn MA, Burden FR, McNaughton. D. An Investigation into FTIR spectroscopy as a biodiagnostic tool for cervical cancer. Biospectroscopy. 1996; 2:143-153. doi: 10.1002/ (sici)1520-6343(1996)2:3<143::aid-bspy1>3.0.co;2-9.

23. Sondi I, Salopek-Sondi B. Silver nanoparticles as antimicrobial agent: a case study on E. coli as a model for Gram-negative bacteria. J Colloid Interface Sci, 2004; 275: 177-182. http://dx.doi. org/10.1016/j.jcis.2004.02.012.

24. Rao PPS, Rao S, Karmarkar SM. Antibacterial activity from Indian species of Sargassum. Bot. Mar. 1988; 31: 295-298.http://dx.doi. org/10.1515/botm.1988.31.4.295

25. Shelat Y. Ph.D. Thesis, Saurashra University, Rajkot, India, 1979.

Copyright:(c) 2012 P. Kumar, et al. This is an openaccess article distributed under the terms of the Creative Commons Attribution License, which permits unrestricted use, distribution, and reproduction in any medium, provided the original author and source are credited.
13. Song JY, Kim BS. Rapid biological synthesis of silver nanoparticles 